\title{
Efficacy of metabolites of a Streptomyces strain (AS1) to control growth and mycotoxin production by Penicillium verrucosum, Fusarium verticillioides and Aspergillus fumigatus in culture
}

\author{
A. Mohd Danial ${ }^{1,2} \cdot$ A. Medina ${ }^{1} \cdot$ M. Sulyok ${ }^{3} \cdot$ N. Magan ${ }^{1}$ (D)
}

Received: 8 November 2019 /Revised: 2 January 2020 / Accepted: 15 January 2020 / Published online: 20 January 2020

(C) The Author(s) 2020

\begin{abstract}
The objectives of this study were to determine the efficacy of metabolites of a Streptomyces strain AS1 on (a) spore germination, (b) mycelial growth, (c) control of mycotoxins produced by Penicillium verrucosum (ochratoxin A, OTA), Fusarium verticillioides (fumonisins, FUMs) and Aspergillus fumigatus (gliotoxin) and (d) identify the predominant metabolites involved in control. Initial screening showed that the Streptomyces AS1 strain was able to inhibit the mycelial growth of the three species at a distance, due to the release of secondary metabolites. A macroscopic screening system showed that the overall Index of Dominance against all three toxigenic fungi was inhibition at a distance. Subsequent studies showed that the metabolite mixture from the Streptomyces AS1 strain was very effective at inhibiting conidial germination of $P$. verrucosum, but less so against conidia of A. fumigatus and $F$. verticillioides. The efficacy was confirmed in studies on a conducive semi-solid YES medium in BioScreen C assays. Using the BioScreen C and the criteria of Time to Detection (TTD) at an OD $=0.1$ showed good efficacy against $P$. verrucosum when treated with the Streptomyces AS1 extract at 0.95 and 0.99 water activity $\left(a_{\mathrm{w}}\right)$ when compared to the other two species tested, indicating good efficacy. The effective dose for $50 \%$ control of growth $\left(\mathrm{ED}_{50}\right)$ at 0.95 and $0.99 a_{\mathrm{w}}$ were approx. $0.005 \mathrm{ng} / \mathrm{ml}$ and $0.15 \mu \mathrm{g} / \mathrm{ml}$, respectively, with the minimum inhibitory concentration (MIC) at both $a_{\mathrm{w}}$ levels requiring $>40 \mu \mathrm{g} / \mathrm{ml}$. In addition, OTA production was completely inhibited by $2.5 \mu \mathrm{g} / \mathrm{ml}$ AS1 extract at both $a_{\mathrm{w}}$ levels in the in vitro assays. Ten metabolites were identified with four of these being predominant in concentrations $>2 \mu \mathrm{g} / \mathrm{g}$ dry weight biomass. These were identified as valinomycin, cyclo(L-Pro-L-Tyr), cyclo(L-Pro-L-Val) and brevianamide F.
\end{abstract}

Keywords Streptomycetaceae $\cdot$ Antifungal metabolites $\cdot$ Fungal pathogens $\cdot$ In vitro efficacy $\cdot$ Mycotoxins $\cdot$ Germination . Mycelial growth

\section{Introduction}

There has been interest in the utilization of actively growing natural microorganisms for the competitive exclusion of

N. Magan

n.magan@cranfield.ac.uk

1 Applied Mycology Group, Environment and AgriFood Theme, Cranfield University, Cranfield, Bedford MK43 0AL, UK

2 Present address: Science and Food Technology Research Centre, Malaysian Agricultural and Research Institute,

43400 Serdang, Selangor, Malaysia

3 Institute of Bioanalytics and Agro-Metabolomics, Department of Agrobiotechnology (IFA-Tulln), University of Natural Resources and Life Sciences, Vienna, Konrad Lorenzstr. 20,

A-3430 Tulln, Austria toxigenic fungal species or by using their naturally produced metabolites for inhibiting the germination and growth of these pathogens that cause diseases of humans and contaminate food and feed (Dogi et al. 2013; Faheem et al. 2015; Guo et al. 2011). A key driver is the strict legislative limits, which exist in many countries for mycotoxins in a range of raw and processed staple commodities. Thus, minimization strategies are actively being sought to reduce potential exposure to spoilage and toxigenic moulds in food and feed chains. There is thus interest in the identification of natural compounds that may control or reduce mycotoxigenic mould colonization and toxin contamination of staple commodities.

Food and feeds such as cereals, nuts and spices are commonly contaminated with mycotoxigenic fungi and mycotoxins that are a serious problem faced by many countries (Lee and Ryu 2017). This causes significant losses to producer countries when their exports are rejected because they do not 
meet the legislative limits, especially in Europe. The Rapid Alert System for Food and Feed shows that up to $30 \%$ of commodities imported into the EU are rejected because of mycotoxin contamination (RASFF 2018). Species from the genera Penicillium, Fusarium and Aspergillus are of greatest concern in terms of mycotoxin contamination of food and feed. A survey conducted in 2014 revealed that more than half of the worlds' regions were severely affected by mycotoxins including fumonisins (FUMs), deoxynivalenol (DON) and zearalenone (ZON) from Fusarium species which had increased when compared to 2013 (Kovalsky 2015). Moreover, the maximum and average ochratoxin A (OTA) concentration in samples from Europe in 2017 was the highest when compared to other regions (Biomin 2018). In a 4-year survey by Limay-Rios et al. (2017) of stored wheat in Canada, Penicillium verrucosum was commonly isolated, as well as contamination with OTA, ochratoxin B (OTB) and citrinin.

Aspergillus fumigatus is an opportunistic fungal species, responsible for aspergillosis due to lung infection. Resistance to azoles has resulted in a number of virulent strains which have become difficult to control (Chowdhary et al. 2013), especially in immunocompromised age groups (Steinbach et al. 2012). A. fumigatus also produces the mycotoxin gliotoxin (GLI) (Kupfahl et al. 2008). Indeed, in Manchester, UK, azole-resistant strains were first detected in 1999 (Howard et al. 2009) and are now commonly found in Switzerland, USA, India and China (Hurst et al. 2017; Lockhart et al. 2011; Riat et al. 2018). However, at the present time, no regulations exist with regard to GLI exposure.

Streptomyces species are gram-positive filamentous bacteria, which can grow in various ecosystems, including sea sponges (Han et al. 2009), soil (Nguyen et al. 2015), animal faeces (Wang et al. 2014) and termites (Zhang et al. 2013). They are able to produce both secondary metabolites (Wang et al. 2013; Zhang et al. 2013) and hydrolytic enzymes (Karthik et al. 2015; Nagpure and Gupta 2013) or potentially novel anti-microbial compounds (Yang et al. 2015; Yekkour et al. 2015; Shakeel et al. 2018). Some compounds have been shown to inhibit spore germination (Wang et al. 2013; Zhang et al. 2013) and mycelial growth of spoilage fungi (Nguyen et al. 2015). However, many studies have screened metabolites for efficacy only against mycelial growth with less emphasis on control of mycotoxin production or in relation to different interacting environmental conditions. There have thus been significant research efforts to screen, isolate and identify novel compounds with antifungal activities from Streptomyces strains.

Previously, Sultan and Magan (2011) examined a Streptomyces strain (AS1) isolated from peanuts. This was found to be competitive and some extracts from the culture were found to be very effective at inhibiting Aspergillus flavus and aflatoxin $\mathrm{B}_{1}$ production, both in vitro and in stored peanuts. However, this Streptomyces strain and its metabolites have not previously been screened against other spoilage toxigenic moulds or indeed against any human fungal diseasecausing pathogens or for control of toxin biosynthesis. In addition, the compounds responsible for the inhibition were not previously identified. The objectives of this study were to determine the efficacy of the Streptomyces AS1 metabolites on (a) spore germination and mycelial growth of $P$. verrucosum, Fusarium verticillioides and A. fumigatus, (b) efficacy for control of the production of OTA, FUMs and GLI and (c) to identify the major metabolites produced by the Streptomyces AS1 strain responsible for the control achieved.

\section{Materials and methods}

\section{Bacterial strain}

A Streptomyces AS1 strain was obtained from the Applied Mycology Collection, Cranfield University. This strain was previously isolated from Egyptian peanuts by Dr. Y. Sultan (Sultan and Magan 2011). This strain was subsequently identified as Streptomyces parvus based on molecular analyses (99\%; EU accession number: EU841619.1).

\section{Mycotoxigenic fungal strains}

Fusarium verticillioides was from the Applied Mycology Collection, Cranfield University. It was isolated from maize by Dr. N.I.P. Samsudin and molecularly identified (Samsudin et al. 2017) and Penicillium verrucosum (OTA11) and Aspergillus fumigatus (strain Mi538) were kindly provided by Dr. M. Olsen (National Food Administration, Uppsala, Sweden). These fungal strains have all previously been demonstrated to produce high titres of their respective toxins (Cairns-Fuller et al. 2005; Samsudin et al. 2017).

\section{Preparation of spore suspensions}

Streptomyces AS1 and test mycotoxigenic fungi A glycerol stock solution of Streptomyces AS1 was inoculated on half nutrient agar $(1 / 2 \mathrm{NA})$ and incubated at $25^{\circ} \mathrm{C}$ for 5 days or until sporulation had occurred. The colonies were flooded with sterile $10 \mathrm{ml}$ of $0.1 \%$ (w/v) Tween-80/water solution and harvested by gently scraping the colony with a sterile spreader to release the spores and this was then transferred aseptically into a sterile $50-\mathrm{ml}$ conical tube and the density adjusted to 1.0 at $\mathrm{OD}_{600}$ or approximate $10^{8}$ spores $/ \mathrm{ml}$.

A. fumigatus and $F$. verticillioides were grown on malt extract agar (MEA; Oxoid Ltd) and P. verrucosum on potato dextrose agar (PDA, Oxoid Ltd) for 7 to 10 days or until sporulation occurred at 25 and $30{ }^{\circ} \mathrm{C}$ (A. fumigatus only). Fungal spores were harvested by pouring $10 \mathrm{ml}$ of sterile $0.1 \%$ Tween-80/water solution onto the agar surface 
containing the cells or spores and gently scraping with a surface-sterilized glass rod. The cell/spore suspensions were transferred into sterile 50-ml tubes, centrifuge at $2000 \mathrm{rpm}$ for 2 min and the supernatants discarded. Fresh sterile $0.1 \%$ Tween-80/water was added. The concentration of fungal spores was counted using a haemocytometer (Thoma, Germany) and adjusted to approx. $10^{6} / \mathrm{ml}$ with sterile $0.1 \%$ Tween-80/water solution.

Spore germination assays: media preparation, inoculation and incubation Molten cooled autoclaved $1 / 2 \mathrm{NA}$ was poured into Petri plates $(90 \mathrm{~mm} \varnothing)$ in a sterile flow bench and allowed to solidify. The cooled media were overlaid with a sheet of sterile cellophane $(8.5 \mathrm{~cm}$ diameter) carefully to avoid any air bubbles. A single colony of Streptomyces AS1 was streak plated on the $1 / 2 \mathrm{NA}$ previously overlaid with a sterile cellophane sheet and incubated at $25{ }^{\circ} \mathrm{C}$ for 10 days. At different time intervals (days 2, 5 and 10), the cellophane layer with the Streptomyces AS1 biomass was carefully removed and $100 \mu 1$ of spore suspension $\left(10^{6}\right.$ spores $\left./ \mathrm{ml}\right)$ of the test pathogens was spread plated onto the agar surface with a sterile glass spreader. These Petri plates were then incubated for $48 \mathrm{~h}$. P. verrucosum and $F$. verticillioides were incubated at $25^{\circ} \mathrm{C}$ and A. fumigatus treatments at $30^{\circ} \mathrm{C}$. After 24 and $48 \mathrm{~h}$, two agar plugs $(18 \mathrm{~mm} \varnothing)$ were taken randomly and placed on a glass slide. They were stained with lactophenol cotton blue, covered with a coverslip prior to microscopic examination. A total of 50 spores in each of four fields were counted in each replicate and the number recorded. Spores were considered germinated when the germ tube length was equal to or greater than the spore diameter (Magan 1988). The experiments were all carried out with three replicates per treatment and repeated once.

\section{Mycelial growth and mycotoxin assays}

Preparation of cell-free supernatant for growth and mycotoxin inhibition assays The Streptomyces AS1 spore suspension $(200 \mu \mathrm{l})$ was inoculated into $200 \mathrm{ml} 1 / 2$ strength sterile nutrient broth (NB) and incubated at $30^{\circ} \mathrm{C}$ at $200 \mathrm{rpm}$ for 4 days. After 4 days, the supernatant was separated from the mycelium by filtration using Whatman filter paper no. 4.

Extraction of Streptomyces AS1 bioactive metabolites using ethyl acetate Bioactive metabolites from the Streptomyces AS1 supernatant were extracted three times with ethyl acetate (EA) (Sultan and Magan 2011). Approx. $900 \mathrm{ml}$ of cell-free supernatant was mixed with $300 \mathrm{ml}$ of EA in a separating funnel and after shaking for a few seconds, the mixture was left to separate into two layers. The EA layer (upper layer) containing the bioactive metabolites was collected and the extraction phase was repeated three times. The EA layers containing the bioactive metabolites were combined and the solvent was removed using a rotary evaporator at $38^{\circ} \mathrm{C}$. The dried film was dissolved in DMSO under sterile conditions for performing the assays.

\section{Efficacy of Streptomyces AS1 EA extract against fungal pathogens using the BioScreen $C$ turbidimetric assay}

Preparation of culture medium The culture medium used to inoculate the fungal pathogen was prepared as described by Medina et al. (2012). Water was used to prepare the medium and this was adjusted with glycerol to 0.99 and 0.95 water activity $\left(a_{\mathrm{w}}\right)$. The culture media used were semi-solid YES (yeast extract sucrose) for P. verrucosum and A. fumigatus and PD for $F$. verticillioides. Each culture medium contained the following: (1) YES: yeast extract $20 \mathrm{~g} / \mathrm{l}$, sucrose $150 \mathrm{~g} / \mathrm{l}$, $\mathrm{MgSO}_{4} \cdot \mathrm{H}_{2} \mathrm{O} 0.5 \mathrm{~g} / \mathrm{l}$ and $0.05 \%$ agar $(\mathrm{w} / \mathrm{v})$ and (2) PD: potato extract $4 \mathrm{~g} / 1$, dextrose $20 \mathrm{~g} / 1$ and $0.03 \%$ agar. Both culture media were sterilized at $121{ }^{\circ} \mathrm{C}$ for $15 \mathrm{~min}$.

Culture medium containing AS1 ethyl acetate extract and spore suspensions A mixture of $9800 \mu \mathrm{l}$ culture medium, $100 \mu \mathrm{l}$ of spore suspensions (final spore count $10^{5}$ spores/ $\mathrm{ml}$ ) and $100 \mu \mathrm{l}$ of EA extract (final concentrations of $5 \mu \mathrm{g} / \mathrm{ml}, 10 \mu \mathrm{g} / \mathrm{ml}, 20 \mu \mathrm{g} / \mathrm{ml}, 30 \mu \mathrm{g} / \mathrm{ml}$ and $40 \mu \mathrm{g} / \mathrm{ml} ; \mathrm{w} / \mathrm{v}$ ) was prepared in sterile $25-\mathrm{ml}$ universal bottles. A total of $300 \mu \mathrm{l}$ of the mixture were loaded into 100 -well microtitre plates and the density measured automatically at $600 \mathrm{~nm}$ every 30 min at $25{ }^{\circ} \mathrm{C}$ for 7 days for $P$. verrucosum and F. verticillioides and at $37^{\circ} \mathrm{C}$ for A. fumigatus. This method was based on that developed for screening compounds for efficacy against filamentous fungi using the BioScreen $\mathrm{C}$ bioassay (Medina et al. 2012). Each set of experiments was carried out with ten replicates. The relative time to reach an absorbance value of 0.1 (time to detection; TTD-0.1) was then compared as an indication of growth rates. The raw data was analysed using Microsoft Excel to obtain the growth curve for the fungal species. The TTD of 0.1 , minimum inhibitory concentrations (MIC) and $\mathrm{IC}_{50}$ concentrations were calculated using the Lambert-Pearson model (Lambert and Pearson 2000).

\section{Agar medium containing EA extract and inoculation of fungal spores}

Approximately $100 \mu \mathrm{l}$ of the different concentrations of the EA extract $(0-40 \mu \mathrm{g} / \mathrm{ml})$ was added aseptically into $10 \mathrm{ml}$ sterile YES (for $P$. verrucosum and A. fumigatus) and PD (for $F$. verticillioides) agar $\left( \pm 52^{\circ} \mathrm{C}\right.$ ) with different $a_{\mathrm{w}}$ levels ( 0.99 and 0.95$)$ and inverted several times before pouring into Petri plates $(53 \mathrm{~mm} \varnothing)$. After the agar media had solidified, $100 \mu \mathrm{l}$ of spore suspension $\left(10^{7}\right.$ spores $\left./ \mathrm{ml}\right)$ was spread plated using a surface-sterilized glass spreader and incubated at 
$25{ }^{\circ} \mathrm{C}$ for $P$. verrucosum and $F$. verticillioides and $37{ }^{\circ} \mathrm{C}$ for A. fumigatus for 7 days. After 7 days, the agar plugs were collected for mycotoxin analysis.

\section{Extraction and quantification of ochratoxin A, gliotoxin and fumonisins}

Ochratoxin A A total of five agar plugs of $P$. verrucosum after 7 days growth on YES medium were randomly collected across the colony using a sterile cork borer (number 5) and transferred into pre-weighed 2-ml tubes and re-weighed to obtain the weight of the agar plug. The extraction of ochratoxin A (OTA) from the agar plug was carried out using $1 \mathrm{ml}$ of methanol. The samples were shaken at $200 \mathrm{rpm}$ and $30{ }^{\circ} \mathrm{C}$ in the dark for $1 \mathrm{~h}$. Samples were then centrifuged at $15,000 \mathrm{~g}$ for $5 \mathrm{~min}$ and the methanol containing OTA was filtered (nylon syringe filter, $0.22 \mu \mathrm{m}$ pore size, Fisher) into amber and silanized HPLC vials (Agilent, UK) for analysis.

The separation and quantification of OTA was done using an Agilent 1200 Series HPLC system (Agilent, UK) with a fluorescence detector. The separation was done at $25^{\circ} \mathrm{C}$ using a Poroshell 120 EC-C18 $(4.6 \mathrm{~mm} \times 100 \mathrm{~mm}, 2.7 \mu \mathrm{m})$ column fitted with a guard column $(4 \mathrm{~mm} \times 3 \mathrm{~mm}$ cartridge, Phenomenex, USA). The mobile phase was water:acetonitrile:acetic acid $(41: 57: 2, \mathrm{v} / \mathrm{v} / \mathrm{v})$. The flow rate and injection volume were $1 \mathrm{ml} / \mathrm{min}$ and $20 \mu \mathrm{l}$, respectively. The detection wavelength was $333 \mathrm{~nm}$ for excitation and $460 \mathrm{~nm}$ for emission. Different concentrations of OTA standards $(0-400 \mathrm{ng} / \mathrm{ml})$ were prepared by dissolving OTA standard (Sigma) solution in methanol $\left(R^{2}=0.9994\right)$. The LOD and LOQ were $12.3 \mathrm{ng} / \mathrm{ml}$ and $41.1 \mathrm{ng} / \mathrm{ml}$, respectively.

Gliotoxin The agar plugs of the growing colonies were obtained as described previously for OTA. The extraction was carried out using chloroform $(1 \mathrm{ml})$ for $1 \mathrm{~h}$ at $30^{\circ} \mathrm{C}$ and shaken at $200 \mathrm{rpm}$. After this, $800 \mu \mathrm{l}$ chloroform containing gliotoxin (GLI) was transferred into a new 2-ml tube and dried overnight in a fume cupboard. The dried extract was dissolved in $700 \mu \mathrm{l}$ of mobile phase solution (1\% acetic acid:acetonitrile $(75: 25, \mathrm{v} / \mathrm{v})$ and filtered into amber and silanized HPLC vials for analysis.

The separation and quantification of GLI was done according to Alonso et al. (2016) with slight modification. The GLI concentration was measured using a reversed-phase HPLC system linked to a diode array detector (DAD). The separation was done at $25{ }^{\circ} \mathrm{C}$ using a Zorbax Eclipse XDBC18 (4.6 mm $\times 150 \mathrm{~mm}, 5.0 \mu \mathrm{m}$, Agilent, USA) column fitted with a guard column $(4 \mathrm{~mm} \times 3 \mathrm{~mm}$ cartridge, Phenomenex, USA). The mobile phase was acetic acid:water $(1: 99, \mathrm{v} / \mathrm{v})$ (eluent A) and acetonitrile (eluent B). The flow rate, injection volume and detection wavelength were $1.3 \mathrm{ml} / \mathrm{min}, 50 \mu \mathrm{l}$ and $268 \mathrm{~nm}$ respectively. The gradient programme was $25 \% \mathrm{~B}$ for $10 \mathrm{~min}$ followed by rapid increased to $100 \%$ in $1 \mathrm{~min}$ and this was held for 8 min before decreasing this to $25 \%$ in $2 \mathrm{~min}$. Working GLI standard solution with a concentration range from 0 to $3000 \mathrm{ng} / \mathrm{ml}$ was prepared by diluting GLI standard (Sigma) in mobile phase $\left(R^{2}=0.9999\right)$. The LOD and LOQ were $41 \mathrm{ng} / \mathrm{ml}$ and $138 \mathrm{ng} / \mathrm{ml}$, respectively.

Fumonisins Fumonisins $\mathrm{B}_{1}$ and $\mathrm{B}_{2}\left(\mathrm{FB}_{1}, \mathrm{FB}_{2}\right)$ are the main mycotoxins in the suite produced by $F$. verticillioides. The agar plugs were extracted by adding $1 \mathrm{ml}$ of acetonitrile:water $(50: 50, \mathrm{v} / \mathrm{v})$ and shaking the mixture at $200 \mathrm{rpm}$ for $1 \mathrm{~h}$ at $30^{\circ} \mathrm{C}$. Acetonitrile: water $(50: 50, \mathrm{v} / \mathrm{v})$ containing $\mathrm{FB}_{1}$ and $\mathrm{FB}_{2}$ was then filtered into amber and silanized HPLC vials for analysis.

The separation and quantification of FBs was done using the HPLC-FLD system (Agilent, UK). The separation was done using a Zorbax Eclipse Plus C18 $(4.6 \mathrm{~mm} \times 150 \mathrm{~mm}$, $3.5 \mu \mathrm{m}$ ) column + a guard column (security guard, $4 \mathrm{~mm} \times$ $3 \mathrm{~mm}$ cartridge, Phenomenex, USA) at $30^{\circ} \mathrm{C}$. The detection was at $335 \mathrm{~nm}$ for the excitation and $440 \mathrm{~nm}$ for the emission wavelength. The mobile phase was $50 \mathrm{mM} \mathrm{NaH}_{2} \mathrm{PO}_{4}(\mathrm{pH}$ 4.01):methanol (50:50, v/v) (eluent A) and acetonitrile:water (80:20) (eluent B). The injection volume was $15 \mu \mathrm{l}$ with a flow rate of $1 \mathrm{ml} / \mathrm{min}$. The gradient programme was $0 \% \mathrm{~B}$ for $5 \mathrm{~min}$, increasing B to $50 \%$ in $1 \mathrm{~min}$ and held for $7.10 \mathrm{~min}$ before slowly increasing to $80 \%$ in $6.90 \mathrm{~min}$. Before injecting the standards or samples, $10 \mu \mathrm{l}$ of standards or samples was mixed with $5 \mu$ l of derivatization solution (OPA). The derivatization solution consisted of $1 \mathrm{ml}$ ortho-phthaldialdehyde ( $40 \mathrm{mg}$ of OPA in $1 \mathrm{ml}$ absolute methanol), $5 \mathrm{ml}$ of $0.1 \mathrm{M}$ $\mathrm{Na}_{2} \mathrm{~B}_{4} \mathrm{O}_{7} \cdot 10 \mathrm{H}_{2} \mathrm{O}$ and $50 \mu \mathrm{l}$ of 2-mercaptoethanol. The derivatization was carried out with an auto-derivatization programme in the HPLC system. Different concentrations of FB standards $(0-5 \mu \mathrm{g} / \mathrm{ml})$ were prepared by diluting FB standard solution (Sigma-Aldrich, USA) in acetonitrile:water (50:50, v/v) $\left(R^{2}=\right.$ 0.9972 for $\mathrm{FB}_{1}$ and 0.9959 for $\mathrm{FB}_{2}$ ). The LOD and LOQ were $0.37 \mu \mathrm{g} / \mathrm{ml}$ and $1.21 \mu \mathrm{g} / \mathrm{ml}$ for $\mathrm{FB}_{1}$ and $0.44 \mu \mathrm{g} / \mathrm{ml}$ and $1.48 \mu \mathrm{g} / \mathrm{ml}$ for $\mathrm{FB}_{2}$, respectively.

\section{Identification of bioactive compounds from Streptomyces AS1 EA extract}

Sample preparation, detection and quantification were performed as described by Malachová et al. (2014). Briefly, the extraction solvent (acetonitrile/water/acetic acid; 79/20/1) was added to dried ethyl acetate extract and after shaking and centrifugation, the extract was injected into LC-MS/MS equipped with a TurboV electrospray ionization (ESI) source. The Phenomenex C18-column $(150 \times 4.6 \mathrm{~mm}, 5 \mu \mathrm{m})$ fitted with a $\mathrm{C} 18$ security guard cartridge $(4 \times 3 \mathrm{~mm})$ was used to separate the compounds. The mobile phases consisted of methanol/water/acetic acid with the ratio of 10/89/1 (v/v/v) for eluent A and 92/2/1 (v/v/v) for eluent B. Both eluents contain $5 \mathrm{mM}$ ammonium acetate. 
Fig. 1 Effect of interaction between Streptomyces AS1 and fungal pathogens on the fungal colony area. Each value is a mean of three replicates \pm SD. Different letters indicate significant difference $(p<0.05)$ within the treatment

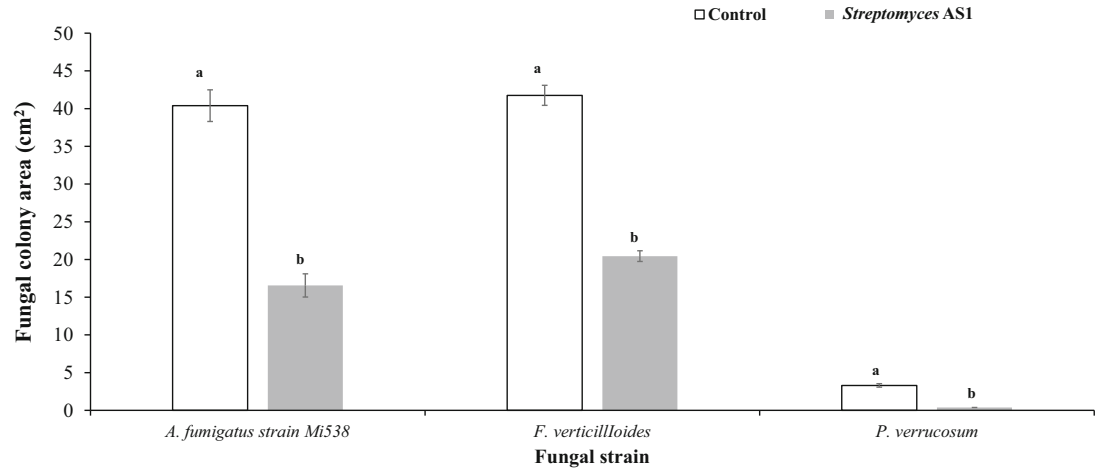

\section{Dual-culture assays}

Single colonies of the Streptomyces AS1 were inoculated onto $1 / 2 \mathrm{NA}$ as a $2-\mathrm{cm}$ streak approximately $2 \mathrm{~cm}$ from the $9-\mathrm{cm}$ Petri plate edge. After incubation at $25^{\circ} \mathrm{C}$ for $48 \mathrm{~h}$, an amount of $5 \mu \mathrm{l}$ of fungal spore suspension $\left(10^{6}\right.$ spores $\left./ \mathrm{ml}\right)$ was applied at a distance of 3-4 cm from the Streptomyces AS1. A. fumigatus assays were incubated at $30{ }^{\circ} \mathrm{C}$ and the other assays at $25{ }^{\circ} \mathrm{C}$ for 7 days. The inhibition was determined based on the fungal colony area and macroscopic interaction between the dual cultures with each colony given an individual numerical score. These were added up to obtain an overall index of dominance $\left(I_{\mathrm{D}}\right)$ as developed by Magan and Lacey (1984). Each interacting species was given an individual score based on the following numerical scores: 1:1-mutual intermingling, 2:2-mutual antagonism on contact, 3:3-mutual antagonism at a distance, 4:0 - dominance of one species on contact and 5:0 - dominance of one species over the other at a distance. All the experiments were done with three triplicates per treatment and repeated once.

\section{Statistical analysis}

Normal distribution of data was checked by the ShapiroWilk $W$ test. The general influence of antifungal extract on fungal growth and mycotoxin production were checked

\begin{tabular}{|c|c|c|}
\hline $\begin{array}{l}\text { Table } 1 \text { Mean } \\
\text { concentrations of } \\
\text { compounds isolated } \\
\text { from ethyl acetate extract }\end{array}$ & Compounds & $\begin{array}{l}\text { Concentration } \\
\text { ( } \mu \mathrm{g} / \mathrm{g} \text { dried } \\
\text { biomass) }\end{array}$ \\
\hline supernatant. The major & Valinomycin & 150 \\
\hline compounds are in italics & Cyclo(L-Pro-L-Tyr) & 22 \\
\hline & Cyclo(L-Pro-L-Val) & 10 \\
\hline & Brevianamide $F$ & 3 \\
\hline & Rugulusovin & 1 \\
\hline & Tryptophol & $>1$ \\
\hline & Chloramphenicol & $>1$ \\
\hline & $\begin{array}{l}\text { Monactin, dinactin, } \\
\text { nonactin }\end{array}$ & $>1$ \\
\hline
\end{tabular}

using one-way analysis of variance (ANOVA) for normal distribution and the Kruskal-Wallis tests (rank sums) for non-normally distributed data. Student's $t$ test was further applied to compare the means for each treatment for normally distributed data and the Wilcoxon method (nonparametric comparison) for non-normal distribution datasets. A significance level of $p<0.05$ was used to compare treatment. The JMP Pro (SAS Institute Inc., Cary, NC, USA) was used for these analyses.

\section{Results}

\section{Streptomyces AS1 for control of fungal pathogens using dual-culture assays}

A significant reduction in the colony area $\left(\mathrm{cm}^{2}\right)$ of all the toxigenic fungi occurred in the presence of Streptomyces AS1 culture (Fig. 1). The inhibition was best against $P$. verrucosum (90\%) followed by A. fumigatus strain (Mi538; 59\%) and $F$. verticillioides $(51 \%)$. The interaction score between the Streptomyces AS1 and the isolates of all three species was 5:0, indicating dominance at a distance. The total $I_{\mathrm{D}}$, which was the sum of the individual scores, was thus 15:0 (AS1:mycotoxigenic strain). Indeed, the mycotoxigenic strains of all three species grew away from the Streptomyces AS1 strain. There was no increase in the colony area of the pathogens after day 3 , especially for $P$. verrucosum.

\section{Identification of bioactive compounds from the Streptomyces AS1 strain}

Table 1 shows the major compounds extracted from the ethyl acetate fraction of the Streptomyces AS1 strain biomass. There were four major compounds present. These included valinomycin $(150 \mu \mathrm{g} / \mathrm{g}$ dry biomass), cyclo(L-Pro-L-Tyr) $(22 \mu \mathrm{g} / \mathrm{g})$, cyclo(L-Pro-L-Val) $(10 \mu \mathrm{g} / \mathrm{g})$ and brevianamide $\mathrm{F}$ $(3 \mu \mathrm{g} / \mathrm{g})$. In addition, six very minor compounds common in some food matrices were identified as rugulusovin, 
(a)

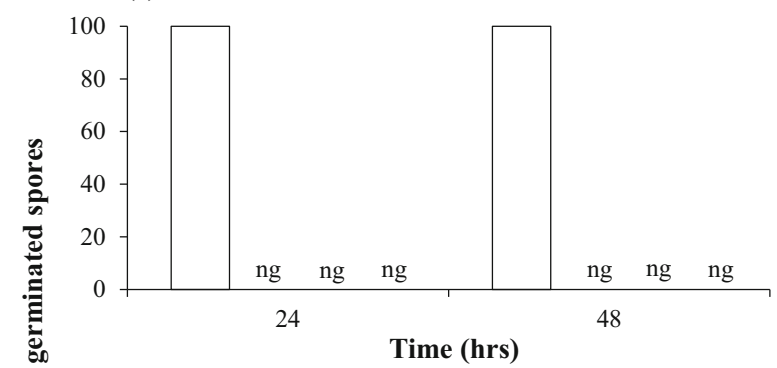

(c)

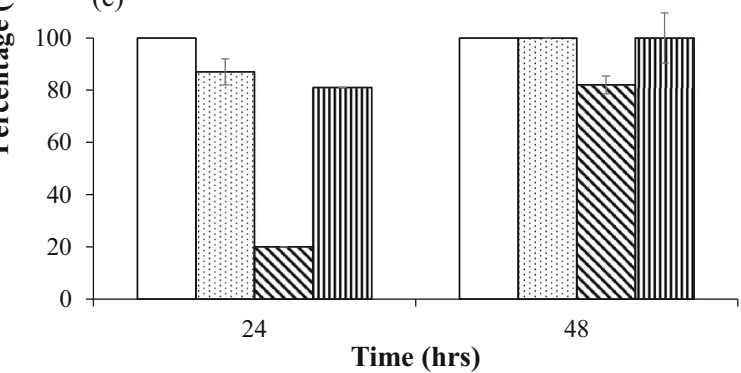

Fig. 2 Mean percentage germination of a P. verrucosum, b A. fumigatus (Mi538) and $\mathbf{c} F$. verticillioides spores on half-strength nutrient agar containing Streptomyces AS1 metabolites. Data are mean of three replicates \pm

tryptophol, chloramphenicol, monactin, dinactin and nonactin (all <0.7 $\mu \mathrm{g} / \mathrm{g}$; Adetunji et al. 2019).

\section{Efficacy of Streptomyces AS1 metabolites for control of spore germination of $P$. verrucosum, $F$. verticillioides and $A$. fumigatus (strain Mi538)}

Figure 2 shows the efficacy of the mixture of metabolites secreted by Streptomyces AS1 on the germination of conidia of $P$. verrucosum, A. fumigatus (Mi538) and $F$. verticillioides. None of the $P$. verrucosum conidia germinated in all the treatment conditions tested. However, $85 \%$ of A. fumigatus conidia germinated after 48 -h incubation. For $F$. verticillioides, there was very little efficacy in controlling microconidial germination. (b)

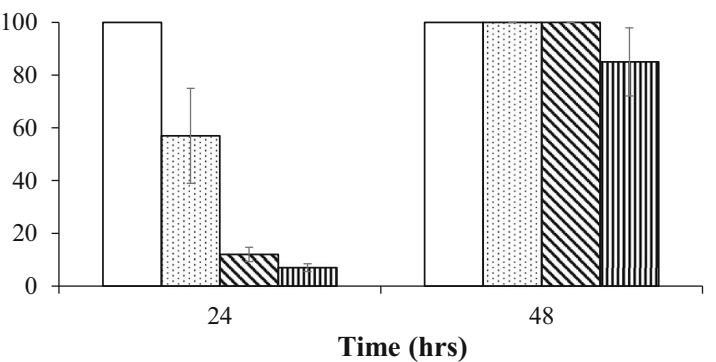

$\square$ Control

고 AS1 (Day 2)

$\checkmark$ AS1 (Day 5)

m AS1 (Day 10)

SD. The data analysis was carried out on the actual data. The percentages were plotted for presentation purposes only. ng no germination

\section{Effect of Streptomyces AS1 ethyl acetate extract on time to detection of $P$. verrucosum, $A$. fumigatus (Mi538) and $F$. verticillioides using the BioScreen assay method}

Figure 3 shows an example of the mean growth curve of $P$. verrucosum and $F$. verticillioides obtained after inoculation with different concentrations of Streptomyces AS1 ethyl acetate extract at $0.95 a_{\mathrm{w}}$ levels over 7 days.

Figure 4 shows the effect of different concentrations of the AS1 ethyl acetate extract at two water activity levels ( 0.99 and $0.95 a_{\mathrm{w}}$ ) on the time to detection (TTD) at an OD equal to 0.1 for $P$. verrucosum, A. fumigatus and $F$. verticillioides. Overall, the TTD of $P$. verrucosum was the highest at both $a_{\mathrm{w}}$ levels, followed by $A$. fumigatus and $F$. verticillioides. For P. verrucosum, AS1 extract at $5 \mu \mathrm{g} / \mathrm{ml}$ resulted in a significant

Fig. 3 Growth curves of a $P$. verrucosum and $\mathbf{b}$ F. verticillioides at $0.95 a_{\mathrm{w}}$ in semi-solid YES media containing different concentrations $(0-$ $40 \mu \mathrm{g} / \mathrm{ml}$ ) of Streptomyces AS1 ethyl acetate extract over 7 days incubation at $25^{\circ} \mathrm{C}$ using the BioScreen C. Each curve represents the mean of ten individual replicates
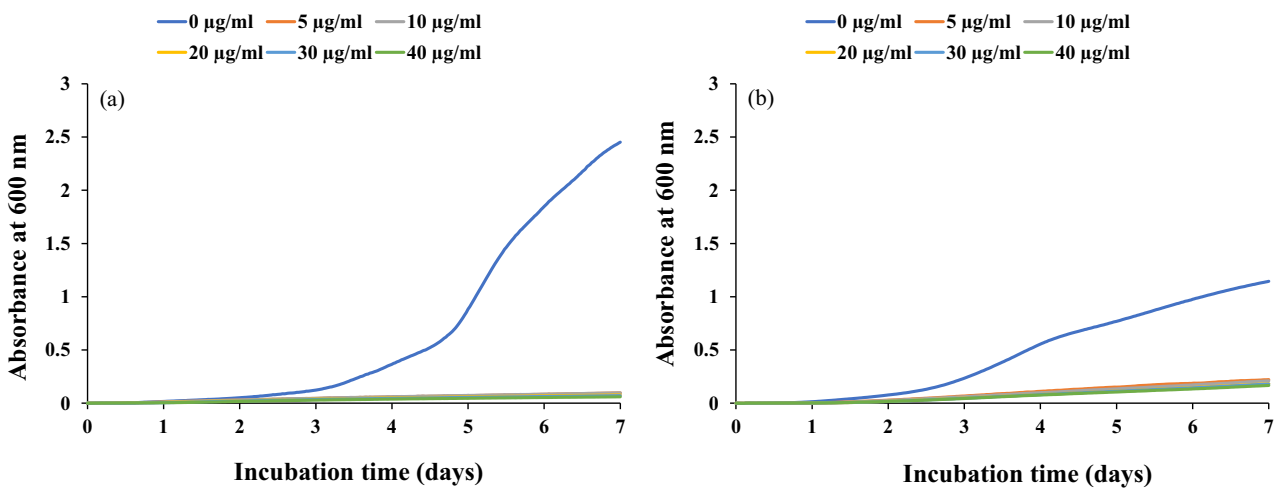

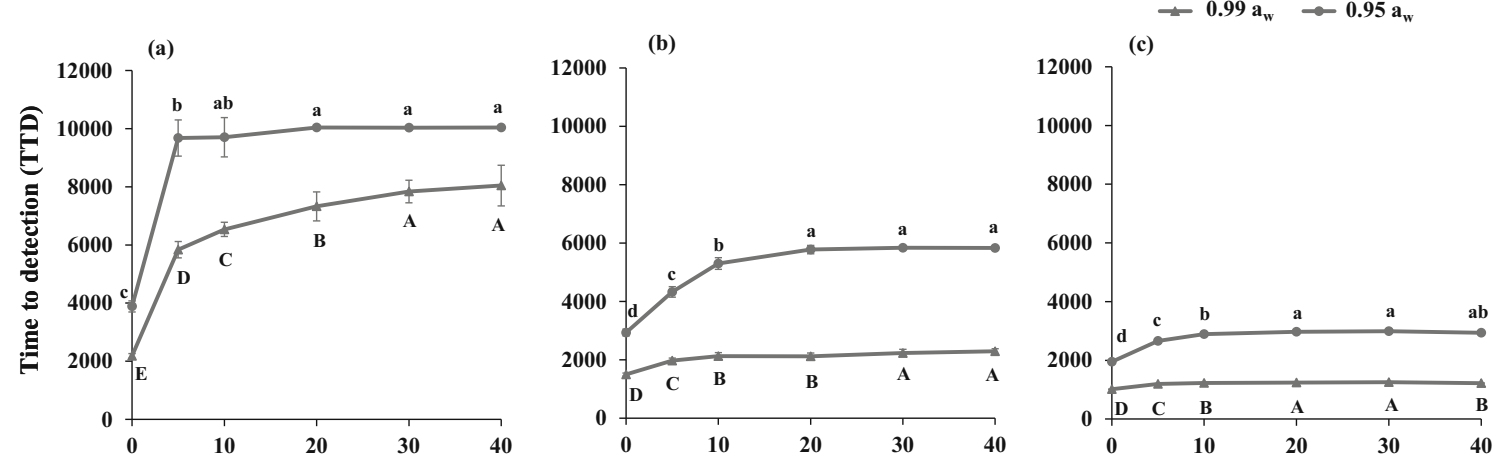

Concentration of ethyl acetate extract $(\mu \mathrm{g} / \mathrm{ml})$

Fig. 4 Effect of Streptomyces AS1 ethyl acetate extract on the time to detection (TTD; optical density of 0.1 at $600 \mathrm{~nm}$ ) for a $P$. verrucosum, b $A$. fumigatus and $\mathbf{c} F$. verticillioides. Data are mean of ten replicates with

increase $(p<0.05)$ of the TTD at both $a_{\mathrm{w}}$ levels indicative of effective control of growth. At $0.99 a_{\mathrm{w}}$, there was a significant increase in the TTD $(p<0.05)$ until $30 \mu \mathrm{g} / \mathrm{ml}$ after which the effect stabilized. For $A$. fumigatus, with freely available water $\left(0.99 a_{\mathrm{w}}\right)$, the TTD was significantly increased until $30 \mu \mathrm{g} / \mathrm{ml}$ concentration. At $0.95 a_{\mathrm{w}}$, this was for concentrations up to $20 \mu \mathrm{g} / \mathrm{ml}$. For $F$. verticillioides, the TTD was significantly increased $(p<0.05)$ with concentrations up to $20 \mu \mathrm{g} / \mathrm{ml}$ of AS1 extract at both $a_{\mathrm{w}}$ levels.

The minimum inhibitory concentration (MIC) and the $\mathrm{IC}_{50}$ concentrations of the AS1 extracts were determined and shown in Table 2. The MIC for P. verrucosum, A. fumigatus (Mi538) and $F$. verticillioides growth at both $a_{\mathrm{w}}$ levels was more than the highest concentration tested $(>40 \mu \mathrm{g} / \mathrm{ml})$. The $\mathrm{IC}_{50}$ for $P$. verrucosum suggested that it was the most sensitive with $0.15 \mu \mathrm{g} / \mathrm{ml}$ and $0.005 \mathrm{ng} / \mathrm{ml}$ at 0.99 and $0.95 a_{\mathrm{w}}$, respectively.

\section{Efficacy of Streptomyces AS1 ethyl acetate extract on mycotoxin production}

The effect of the AS1 extract (Table 3) on mycotoxin production was examined. For $P$. verrucosum, complete control of OTA production was achieved, regardless of $a_{\mathrm{w}}$ level at the

Table 2 Minimum inhibitory concentration (MIC) and $\mathrm{IC}_{50}$ of the Streptomyces AS1 ethyl acetate extract for controlling growth of isolates of $P$. verrucosum, A. fumigatus strain Mi538 and $F$. verticillioides

\begin{tabular}{llll}
\hline Fungal strain & $\begin{array}{l}\text { Water activity } \\
\left(a_{\mathrm{w}}\right)\end{array}$ & $\begin{array}{l}\mathrm{MIC} \\
(\mu \mathrm{g} / \mathrm{ml})\end{array}$ & $\mathrm{IC}_{50}(\mu \mathrm{g} / \mathrm{ml})$ \\
\hline P. verrucosum & 0.99 & $>40$ & 0.15 \\
& 0.95 & $>40$ & 0.000005 \\
A. fumigatus (Mi538) & 0.99 & $>40$ & $>40$ \\
& 0.95 & $>40$ & 10.45 \\
F. verticillioides & 0.99 & $>40$ & $>40$ \\
& 0.95 & $>40$ & $>40$ \\
\hline
\end{tabular}

bars indicating standard deviation. Different letters indicate significant differences $(p<0.05)$ within treatments

lowest concentration tested $(5 \mu \mathrm{g} / \mathrm{ml})$. For gliotoxin, there was relatively little control by the concentration range tested at both $a_{\mathrm{w}}$ levels. Indeed, there appeared to be some stimulation at intermediate concentrations. Even at $40 \mu \mathrm{g} / \mathrm{ml}$, there was no difference between the control and the treatment at both $a_{\mathrm{w}}$ levels. For $F$. verticillioides, there was a significant reduction $(p<0.05)$ in $\mathrm{FB}_{1}$ and $\mathrm{FB}_{2}$ at both $a_{\mathrm{w}}$ levels when compared with the control. AS1 concentrations of 5-40 $\mu \mathrm{g} / \mathrm{ml}$ gave similar inhibition of $\mathrm{FB}_{1}$ at both $a_{\mathrm{w}}$ levels and $\mathrm{FB}_{2}$ at $0.95 a_{\mathrm{w}}$. For $\mathrm{FB}_{2} / 0.99 a_{\mathrm{w}},>20 \mu \mathrm{g} / \mathrm{ml}$ AS1 was needed to significantly $(p<0.05)$ inhibit production.

For $P$. verrucosum, because no OTA was detected at $5 \mu \mathrm{g} / \mathrm{ml}$ AS1 extract, further studies with lower concentration of AS1 extract were carried out to identify more accurately the concentrations at which complete inhibition of OTA occurred. Figure 5 shows that there was a significant decrease in OTA production at 0.99 and $0.95 a_{\mathrm{w}}$ when the concentration was $1.25 \mu \mathrm{g} / \mathrm{ml}$ and complete inhibition at $\geq 2.5 \mu \mathrm{g} / \mathrm{ml}$. However, at very low concentrations of $0.15 \mu \mathrm{g} / \mathrm{ml}$ and $0.99 a_{\mathrm{w}}$, the OTA production was stimulated when compared with the untreated control.

\section{Discussion}

In the present study, the Streptomyces AS1 strain produced compounds which could control the activity of food spoilage mycotoxigenic fungi and an opportunistic human one. In colony-based interactions, the Streptomyces AS1 generally inhibited all three species tested with an interaction score of 5:0 indicating dominance at the distance and the production of antifungal metabolites. Previous studies with Streptomyces species have been associated with the production of primary and secondary metabolites including hydrolytic enzymes and antibiotic-like compounds (Prapagdee et al. 2008; Taechowisan et al. 2005).

The effect of the mixture of Streptomyces AS1 metabolites on spore germination of strains of $P$. verrucosum, $F$. verticillioides and $A$. fumigatus was dependent on the time 
Table 3 Efficacy of Streptomyces AS1 ethyl acetate extract for control of OTA, gliotoxin and fumonisin production by isolates of $P$. verrucosum, A. fumigatus strain Mi538 and F. verticillioides, respectively. Data are means of three replicates with SE. Different letters (capitals, $0.99 a_{\mathrm{w}}$; lowercase letters, $\left.0.95 a_{\mathrm{w}}\right)$ indicate significant differences $(p<0.05)$ between treatments by Student's $t$ method for gliotoxin at $0.95 a_{\mathrm{w}}$ and the Wilcoxon method (non-parametric comparison) at $0.99 a_{\mathrm{w}}$. $N D$ none detected

\begin{tabular}{|c|c|c|c|c|c|}
\hline \multirow{2}{*}{$\begin{array}{l}\text { AS1 concentration } \\
(\mu \mathrm{g} / \mathrm{ml})\end{array}$} & \multirow{2}{*}{$\begin{array}{l}\text { Water activity } \\
\left(a_{\mathrm{w}}\right)\end{array}$} & \multirow{2}{*}{$\begin{array}{l}\text { OTA } \\
(\mu \mathrm{g} / \mathrm{g} \text { agar })\end{array}$} & \multirow{2}{*}{$\begin{array}{l}\text { Gliotoxin } \\
(\mu \mathrm{g} / \mathrm{g} \text { agar })\end{array}$} & \multicolumn{2}{|c|}{ Fumonisins ( $\mu \mathrm{g} / \mathrm{g}$ agar) } \\
\hline & & & & $\mathrm{FB}_{1}$ & $\mathrm{FB}_{2}$ \\
\hline \multirow[t]{2}{*}{0} & 0.99 & $10.5 \pm 4.9$ & $4.1 \pm 0.76^{\mathrm{A}}$ & $3.73 \pm 0.07^{\mathrm{A}}$ & $4.57 \pm 0.49^{\mathrm{A}}$ \\
\hline & 0.95 & $13.2 \pm 3.1$ & $2.2 \pm 0.44^{\mathrm{cd}}$ & $0.84 \pm 0.01^{\mathrm{a}}$ & $0.96 \pm 0.15^{\mathrm{a}}$ \\
\hline \multirow[t]{2}{*}{5} & 0.99 & ND & $6.9 \pm 0.30^{\mathrm{A}}$ & $0.10 \pm 0.002^{\mathrm{B}}$ & $4.20 \pm 0.15^{\mathrm{A}}$ \\
\hline & 0.95 & ND & $3.8 \pm 0.34^{\mathrm{a}}$ & $0.06 \pm 0.04^{\mathrm{b}}$ & $0.18 \pm 0.04^{\mathrm{b}}$ \\
\hline \multirow[t]{2}{*}{10} & 0.99 & ND & $4.1 \pm 0.20^{\mathrm{A}}$ & $0.09 \pm 0.003^{\mathrm{B}}$ & $4.70 \pm 0.66^{\mathrm{A}}$ \\
\hline & 0.95 & ND & $3.4 \pm 0.70^{\mathrm{ab}}$ & $0.03 \pm 0.01^{\mathrm{b}}$ & $0.09 \pm 0.02^{\mathrm{bc}}$ \\
\hline \multirow[t]{2}{*}{20} & 0.99 & ND & $7.0 \pm 0.03^{\mathrm{A}}$ & $0.07 \pm 0.01^{\mathrm{B}}$ & $2.26 \pm 0.70^{\mathrm{B}}$ \\
\hline & 0.95 & ND & $2.9 \pm 0.14^{\mathrm{bc}}$ & $0.04 \pm 0.002^{\mathrm{b}}$ & $0.07 \pm 0.01^{\mathrm{bc}}$ \\
\hline \multirow[t]{2}{*}{30} & 0.99 & ND & $5.0 \pm 1.10^{\mathrm{A}}$ & $0.06 \pm 0.003^{\mathrm{B}}$ & $1.42 \pm 0.23^{\mathrm{B}}$ \\
\hline & 0.95 & ND & $1.9 \pm 0.06^{\mathrm{d}}$ & $0.03 \pm 0.01^{\mathrm{b}}$ & $0.07 \pm 0.01^{\mathrm{c}}$ \\
\hline \multirow[t]{2}{*}{40} & 0.99 & ND & $4.1 \pm 0.15^{\mathrm{A}}$ & $0.06 \pm 0.03^{\mathrm{B}}$ & $1.32 \pm 0.56^{\mathrm{B}}$ \\
\hline & 0.95 & ND & $2.4 \pm 0.50^{\mathrm{cd}}$ & $0.03 \pm 0.01^{\mathrm{b}}$ & $0.08 \pm 0.01^{\mathrm{bc}}$ \\
\hline
\end{tabular}

frame of cultivation of the Streptomyces AS1 strain. With longer culturing times, more metabolites were produced resulting in better efficacy, especially against $P$. verrucosum. None of the spores germinated under all conditions tested. In contrast, the mixture of compounds was not effective against $A$. fumigatus and $F$. verticillioides although the metabolites did delay germination. Previously, complete inhibition of conidial germination of A. flavus spores by metabolites of Streptomyces AS1 has been reported (Sultan and Magan 2011).

The efficacy of the mixture of the Streptomyces AS1 extract was further examined using a spectrophotometric turbidimetric rapid assay method using the BioScreen $\mathrm{C}$ system. The effects of different concentrations of metabolites from the AS1 strain and water activity $\left(a_{\mathrm{w}}\right)$ on the TTD for $P$. verrucosum, $F$. verticillioides and $A$. fumigatus and on mycotoxin production were studied. The TTD represents the initial growth phase of the fungi. The shorter the TTD, the less effective the mixture of metabolites were on fungal growth. Overall, the AS1 mixed extract was more effective in controlling growth of
$P$. verrucosum, even at low concentrations. This paralleled the findings on effects on conidial spore germination inhibition of the strain of this species. More importantly, the mixed AS1 extract suppressed production of OTA by $P$. verrucosum and also reduced the production of $\mathrm{FB}_{1}$ and $\mathrm{FB}_{2}$ by $F$. verticillioides at both $a_{\mathrm{w}}$ levels examined. Indeed, OTA was not detected when $5 \mu \mathrm{g} / \mathrm{ml}$ of the the AS1 extract was used. Thus, more detailed efficacy testing was done to determine the lowest concentrations which could be used to inhibit OTA production. Complete inhibition of OTA production was achieved at very low concentrations $(2.5 \mu \mathrm{g} / \mathrm{ml})$. Thus, the predominant metabolites produced by the Streptomyces AS1 were fungistatic against spore germination and growth of $P$. verrucosum, and the $\mathrm{IC}_{50}$ concentrations were $<0.20 \mu \mathrm{g} / \mathrm{ml}$ and resulted in complete inhibition of OTA mycotoxin production at both $a_{\mathrm{w}}$ levels tested. However, this did not occur with the A. fumigatus, responsible for aspergillosis of the lungs, where there was no control of gliotoxin production.

Previous studies with other Streptomyces strains have suggested no effect on $P$. verrucosum growth, only some
Fig. 5 Efficacy of Streptomyces AS1 ethyl acetate extract for control of OTA production by P. verrucosum at $25^{\circ} \mathrm{C}$. Data are means of triplicates with bars indicating standard errors. Different letters indicate significant differences $(p<0.05)$ within treatments. n.d. none detected

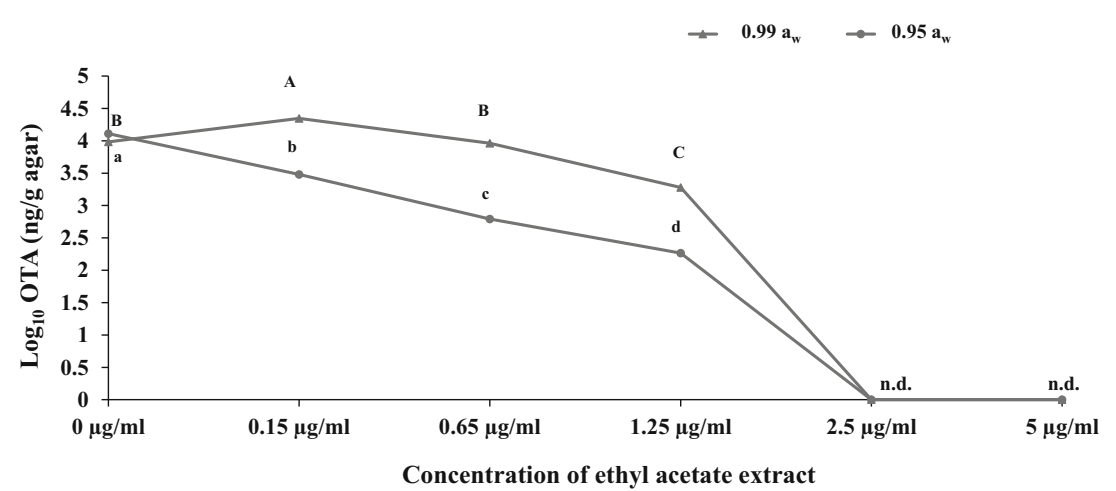


inhibition of A. fumigatus, but good efficacy against F. verticillioides (Nguyen et al. 2018; Paškevičius et al. 2014). However, previous studies only focused on control of mycelial growth and not on mycotoxin production. A previous study by Medina et al. (2007) found compounds from another Streptomyces strain were effective in controlling Aspergillus carbonarius growth and OTA production.

A total of 10 compounds were found to be present in the AS1 ethyl acetate extract. The major compound present was valinomycin $(150 \mu \mathrm{g} / \mathrm{g})$. Three others present which may have contributed to the anti-fungal activity were cyclo(L-Pro-L-Tyr), cyclo(L-Pro-L-Val) and brevianamide F. Comparisons were made between efficacy of the mixed AS1 extract and valinomycin and cyclo(L-Pro-L-Tyr) alone and as a mixture, for which standards are available. These were found to have no effect on growth of the target species when compared with the mixed AS1 metabolites (MohD Danial 2019). This suggests that the combined mixture has much better efficacy than the major individual compound or a mixture of the two main compounds alone.

The production of these compounds by other Streptomyces species and bacteria such as Bacillus sp. N strain, Pseudomonas aurantiaca and Cellulosimicrobium cellulans has been reported previously (Buedenbender et al. 2018; Gwee Kyo et al. 2011; Kumar et al. 2013; Li et al. 2006; Park and Shim 2014; Park et al. 2008, Wattana-Amorn et al. 2016). The other compounds found were mainly cyclic ionophores which were present in very low amounts and thus probably did not directly contribute to the antifungal activity. Previous studies have shown variable results in terms of efficacy depending on the target fungal genera or species including Aspergillus, Fusarium, Penicillium, Rhizoctonia and Candida species (Gwee Kyo et al. 2011; Kumar et al. 2013; Park and Shim 2014; Park et al. 2008). Although brevianamide $\mathrm{F}$ was a relatively minor component, its potential role in antifungal activity has not been previously described.

In conclusion, the mixture of metabolites produced by the Streptomyces AS1 species was more effective in suppressing spore germination and mycelial growth of $P$. verrucosum than of $F$. verticillioides or A. fumigatus. A very low concentration of AS1 extract was able to inhibit mycelial growth of P. verrucosum by $50 \%$ although $>40 \mu \mathrm{g} / \mathrm{ml}$ of the mixture of compounds was needed for complete inhibition. The mixture of metabolites produced by the Streptomyces AS1 successfully inhibited OTA production by $P$. verrucosum completely at concentrations of $2.5 \mu \mathrm{g} / \mathrm{ml}$. The potential for using the mixture of these metabolites now needs to be examined in situ in stored temperate cereals to examine the efficacy for control of colonization by $P$. verrucosum and OTA contamination during short- and medium-term storage.

Acknowledgements We are grateful to Dr. Monica Olsen (National Swedish Food Safety Agency, Sweden) for the supply of the strains of P. verrucosum and A. fumigatus. A.M-D is grateful to MARDI and the Malaysian Government for financial support for completion of her $\mathrm{PhD}$.

\section{Compliance with ethical standards}

Conflict of interest The authors declare that they have no conflicts of interest.

Open Access This article is licensed under a Creative Commons Attribution 4.0 International License, which permits use, sharing, adaptation, distribution and reproduction in any medium or format, as long as you give appropriate credit to the original author(s) and the source, provide a link to the Creative Commons licence, and indicate if changes were made. The images or other third party material in this article are included in the article's Creative Commons licence, unless indicated otherwise in a credit line to the material. If material is not included in the article's Creative Commons licence and your intended use is not permitted by statutory regulation or exceeds the permitted use, you will need to obtain permission directly from the copyright holder. To view a copy of this licence, visit http://creativecommons.org/licenses/by/4.0/.

\section{References}

Adetunji MC, Aroyeun SO, Osho MB, Sulyok M, Krska R, Mwanza M (2019) Fungal metabolite and mycotoxins profile of cashew nut from selected locations in two African countries. Food Add Contam Part A 36:1847-1859

Alonso V, Aminahuel C, Díaz Vergara L, Pereyra C, Poloni V, Dalcero A, Cavaglieri L (2016) Ecophysiology of environmental Aspergillus fumigatus and comparison with clinical strains on gliotoxin production and elastase activity. Lett Appl Microbiol 62:160-168

Biomin (2018) World Mycotoxin Survey 2017. Annual Report no 14. BIOMIN Holdings GmbH, Austria

Buedenbender L, Robertson LP, Lucantoni L, Avery VM, Ke DIK, Carroll AR (2018) Hsqc-tocsy fingerprinting-directed discovery of antiplasmodial polyketides from the marine ascidian-derived Streptomyces sp. (USC-16018). Marine Drugs 16:1-11

Cairns-Fuller V, Aldred D, Magan N (2005) Water, temperature and gas composition interactions affect growth and ochratoxin A production by isolates of Penicillium verrucosum on wheat grain. J Appl Microbiol 99:1215-1221

Chowdhary A, Kathuria S, Xu J, Meis JF (2013) Emergence of azoleresistant Aspergillus fumigatus strains due to agricultural azole use creates an increasing threat to human health. PLoS Pathog 9:1-5

Dogi CA, Fochesato A, Armando R, Pribull B, Souza MMS, De Coelho IS (2013) Selection of lactic acid bacteria to promote an efficient silage fermentation capable of inhibiting the activity of Aspergillus parasiticus and Fusarium gramineraum and mycotoxin production. J Appl Microbiol 114:1650-1660

Faheem M, Raza W, Zhong W, Nan Z, Shen Q, Xu Y (2015) Evaluation of the biocontrol potential of Streptomyces goshikiensis YCXU against Fusarium oxysporum $\mathrm{f}$. sp. niveum. Biological Cont 81:101-110

Guo J, Mauch A, Galle S, Murphy P, Arendt EK, Coffey A (2011) Inhibition of growth of Trichophyton tonsurans by Lactobacillus reuteri. J Appl Microbiol 111:474-483

Gwee Kyo P, Lim JH, Kim SD, Shim SH (2011) Elucidation of antifungal metabolites produced by Pseudomonas aurantiaca IB5-10 with broadspectrum antifungal activity. J Microbiol Biotechnol 22:326-330

Han Y, Yang B, Zhang F, Miao X, Li Z (2009) Characterization of antifungal chitinase from marine Streptomyces sp. DA11 associated with South China sea sponge Craniella australiensis. Mar Biotechnol 11:132-140

Howard SJ, Cerar D, Anderson MJ, Albarrag A, Fisher MC, Pasqualotto AC, Laverdiere M, Arendrup MC, Perlin DS, Denning DW (2009) Frequency and evolution of azole resistance in Aspergillus 
fumigatus associated with treatment failure 1. Emerg Infect Dis 15: 1068-1076

Hurst SF, Berkow EL, Stevenson KL, Litvintseva AP, Lockhart SR (2017) Isolation of azole-resistant Aspergillus fumigatus from the environment in the South-eastern USA. J Antimicrob Chemother 72:2443-2446

Karthik N, Binod P, Pandey A (2015) Purification and characterisation of an acidic and antifungal chitinase produced by a Streptomyces sp. Bioresour Technol 188:195-201

Kovalsky P (2015) Mycotoxin Survey 2014-focus on United States corn harvest. BIOMIN Mycotoxin Survey, BIOMIN Holding $\mathrm{GmbH}$, Austria

Kumar N, Mohandas C, Nambisan B, Soban Kumar DR, Lankalapalli RV (2013) Isolation of proline-based cyclic dipeptides from Bacillus sp. N strain associated with rhabditid entomopathogenic nematode and its antimicrobial properties. World J Microbiol Biotechnol 29:355-364

Kupfahl C, Michalka A, Lass-Flörl C, Fischer G, Haase G, Ruppert T, Geginat G, Hof H (2008) Gliotoxin production by clinical and environmental Aspergillus fumigatus strains. Int J Medical Microbiol 298:319-327

Lambert RJW, Pearson J (2000) Susceptibility testing: accurate and reproducible minimum inhibitory concentration (MIC) and noninhibitory concentration (NIC) values. J Appl Microbiol 88: $784 \mathrm{e} 790$

Li X, Dobretsov S, Xu Y, Xiao X, Hung OS, Qian PY (2006) Antifouling diketopiperazines produced by a deep-sea bacterium, Streptomyces fungicidicus. Biofouling 22:201-208

Lee HJ, Ryu D (2017) Worldwide occurrence of mycotoxins in cereals and cereal-derived food products: public health perspectives of their co-occurrence. J Agric Food Chem 65:7034-7051

Limay-Rios V, Miller JD, Schaafsma AW (2017) Occurrence of Penicillium verrucosum, ochratoxin A, ochratoxin B and citrinin in on-farm stored winter wheat from the Canadian Great Lakes Region. PLoS One 12:1-22

Lockhart SR, Frade JP, Etienne KA, Pfaller MA, Diekema DJ, Balajee SA (2011) Azole resistance in Aspergillus fumigatus isolates from the ARTEMIS global surveillance study is primarily due to the TR/ L98H mutation in the cyp51A gene. Antimicrob Agents Chemother 55:4465-4468

Magan N (1988) Effect of water potential and temperature on spore germination and germ tube growth in vitro and on straw leaf sheaths. Trans Br Mycol Soc 90:97-107

Magan N, Lacey J (1984) The effect of water activity, temperature and substrate on interactions between field and storage fungi. Trans $\mathrm{Br}$ Mycol Soc 82:83-93

Malachová A, Sulyok M, Beltrán E, Berthiller F, Krska R (2014) Optimization and validation of a quantitative liquid chromatography-tandem mass spectrometric method covering 295 bacterial and fungal metabolites including all regulated mycotoxins in four model food matrices. J Chromat A 1362:145-156

Medina A, Lambert RJW, Magan N (2012) Rapid throughput analysis of filamentous fungal growth using turbidimetric measurements with the Bioscreen C: a tool for screening antifungal compounds. Fungal Biol 116:161-169

Medina A, Jiménez M, Mateo R, Magan N (2007) Efficacy of natamycin for control of growth and ochratoxin A production by Aspergillus carbonarius strains under different environmental conditions. J Appl Microbiol 103:2234-2239

Mohd Danial A (2019). Metabolites of lactic acid bacteria (LABs) from Malaysian fermented foods and a Streptomyces sp. for control of fungal growth and mycotoxin production. $\mathrm{PhD}$ Thesis, Cranfield Soil and AgriFood Institute, Cranfield University, Cranfield, beds. MK43 0AL, U.K.

Nagpure A, Gupta RK (2013) Purification and characterization of an extracellular chitinase from antagonistic Streptomyces violaceusniger. J Basic Microbiol 53:429-439
Nguyen XH, Naing KW, Lee YS, Kim YH, Moon JH, Kim KY (2015) Antagonism of antifungal metabolites from Streptomyces griseus H7602 against Phytophthora capsici. J Basic Microbiol 55:45-53

Park SY, Shim SH (2014) Characterization of metabolites from cultures of Cellulosimicrobium cellulans. J Korean Soc Appl Biol Chem 57: 481-484

Park CN, Lee JM, Lee D, Kim BS (2008) Antifungal activity of valinomycin, a peptide antibiotic produced by Streptomyces sp. strain M10 antagonistic to Botrytis cinereal. J Microbiol Biotechnol 18:880-884

Paškevičius A, Švediene J, Levinskaite L, Repečkiene J, Raudoniene V, Melvydas V (2014) The effect of bacteria and essential oils on mycotoxin producers isolated from feed of plant origin. Veterinarija ir Zootechnika 65:52-60

Prapagdee B, Kuekulvong C, Mongkolsuk S (2008) Antifungal potential of extracellular metabolites produced by Streptomyces hygroscopicus against phytopathogenic fungi. Int J Biol Sci 4: 330-337

Rapid Alert System for Food and Feed (RASFF) (2018) The rapid alert system for food and feed-2017 annual report. Luxembourg, European Union, pp 1-53

Riat A, Plojoux J, Gindro K, Schrenzel J, Sanglard D (2018) Azole resistance of environmental and clinical Aspergillus fumigatus isolates from Switzerland. Antimicrob Agents Chemother 62:1-7

Shakeel F, Alshehri S, Haq N, Elzayat E, Ibrahim M, Altamimi MA, Mohsin K, Alanazi FK, Alsarra IA (2018) Solubility determination and thermodynamic data of apigenin in binary Transcutol ${ }^{\circledR}+$ water mixtures. Ind Crop Prod 116:56-63

Steinbach WJ, Marr KA, Anaissie EJ, Azie N, Quan SP, Meier-Kriesche HU, Apewokin S, Horn DL (2012) Clinical epidemiology of 960 patients with invasive aspergillosis from the PATH Alliance registry. $\mathrm{J}$ Inf Secur 65:453-464

Sultan Y, Magan N (2011) Impact of a Streptomyces (AS1) strain and its metabolites on control of Aspergillus flavus and aflatoxin B1contamination in vitro and in stored peanuts. Biocont Sci Technol 21:1437-1455

Taechowisan T, Lu C, Shen Y, Lumyong S (2005) Secondary metabolites from endophytic Streptomyces aureofaciens CMUAc130 and their antifungal activity. Microbiol 151:1691-1695

Wang J, Tan H, Lu Y, Cao L (2014) Determination of ionophore antibiotics nactins produced by faecal Streptomyces from sheep. BioMetals 27:403-407

Wang C, Wang Z, Qiao X, Li Z, Li F, Chen M, Wang Y, Huang Y, Cui H (2013) Antifungal activity of volatile organic compounds from Streptomyces alboflavus TD-1. FEMS Microbiol Letts 341:45-51

Wattana-Amorn P, Charoenwongsa W, Williams C, Crump MP, Apichaisataienchote B (2016) Antibacterial activity of cyclo(LPro-L-Tyr) and cyclo(D-Pro-L-Tyr) from Streptomyces sp. strain 22-4 against phytopathogenic bacteria. Nat Prod Res 30:1980-1983

Yang X, Peng T, Yang Y, Li W, Xiong J, Zhao L, Ding Z (2015) Antimicrobial and antioxidant activities of a new benzamide from endophytic Streptomyces sp. YIM 67086. Nat Prod Res 29:331-335

Yekkour A, Meklat A, Bijani C, Toumatia O, Errakhi R, Lebrihi A, Mathieu F, Zitouni A, Sabaou N (2015) A novel hydroxamic acidcontaining antibiotic produced by a Saharan soil-living Streptomyces strain. Lett Appl Microbiol 60:589-596

Zhang YL, Li S, Jiang DH, Kong LC, Zhang PH, Xu JD (2013) Antifungal activities of metabolites produced by a termiteassociated Streptomyces canus BYB02. J Agric Food Chem 61: $1521-1524$

Publisher's note Springer Nature remains neutral with regard to jurisdictional claims in published maps and institutional affiliations. 